Sharif University of Technology
Scientia Iranica
SCIENTIA
I RAN I C A
http://scientiairanica.sharif.edu

\title{
Environmental impact analysis of high-rise buildings for resilient urban development
}

\author{
H. Vafai ${ }^{a}$, P. Parivar ${ }^{\mathrm{b}}$, S. Sehat Kashani ${ }^{\mathrm{c}}$, A. Farshforoush Imanid ${ }^{\mathrm{d}}$, F. Vakili ${ }^{\mathrm{e}}$, \\ and G. Ahmadi ${ }^{\mathrm{f} *}$
}

a. Department of Civil Engineering and Engineering Mechanics, The University of Arizona, Tucson, Arizona, USA.

b. Department of Environment Science, School of Natural Resources and Desert Studies, Yazd University, Yazd, Iran.

c. Atmospheric Science and Meteorological Research Center (ASEMRC), Tehran, P.O. Box 14977-16385, Iran.

d. School of Mechanical Engineering, Sharif University of Technology, Tehran, Iran.

e. Faculty of Environment, University of Tehran, Tehran, Iran.

f. Department of Mechanical and Aeronautical Engineering, Clarkson University, Potsdam, New York, USA.

Received 2 December 2019; accepted 6 June 2020

\section{KEYWORDS}

Environmental impacts;

Resilience mindset; High-rise buildings; Urban structure; Urban function.

\begin{abstract}
In recent years, the construction of high-rise buildings as an urban development strategy has been accepted in many megacities. High-rise buildings have positive as well as negative impacts on urban environments. Therefore, the environmental impact assessment of high-rise buildings for establishing strategies to ensure sustainable and resilient urban development is essential. In this study, the environmental impact of high-rise buildings with a resilient development mindset was assessed. Resilience mindset provides an approach for including the uncertainties and interdependence of systems and processes for planning new sustainable developments and assessment methods. The corresponding environmental impact assessment was performed by monitoring the structural changes and their impacts on the function of ecosystem and environmental services. Here, the positive and negative impacts of high-rise buildings were evaluated. Protection of impervious surfaces as a positive impact and changing the natural pattern of urban wind flow as a negative impact were considered. The transparency of the results and the reduction of uncertainty are the advantages of using the resilience mindset in the environmental impact assessment. The results of this study suggest that the resilient development mindset can improve the environmental assessment through the adoption of appropriate indicators on multiple scales and differentiating between the primary and secondary effects.
\end{abstract}

(C) 2020 Sharif University of Technology. All rights reserved.

\section{Introduction}

History of Environmental Impact Assessment (EIA) in

* Corresponding author.

E-mail addresses: hvafai@email.arizona.edu (H. Vafai); parivar.p@yazd.ac.ir (P. Parivar);

Sehat.kashani@gmail.com (S. Sehat Kashani); farshforoush_amir@mech.sharif.edu (A.Farshforoush

Imani); Farane.vakili@gmail.com (Farane Vakili);

ahmadi@clarkson.edu (G.Ahmadi)

doi: $10.24200 /$ sci. 2020.21908 the western countries began in 1969 with the adoption of the National Environmental Policy Act of Congress of the United States. EIA was then implemented by many studies in both developed and developing countries $[1,2]$. EIA is a multi-step process in which a wide range of issues are taken into account to determine under which environmental constraints a project should be undertaken. The effectiveness of the EIA system depends on the specific steps involved in reviewing project proposals. In general, the major steps in the EIA process include screening, scoping, the examination of alternatives, impact identification and analysis, impact 
mitigation and management, evaluation of significance, Environmental Impact Statements (EIS), and review of EIS [3].

Conventional EIA methods such as matrix, checklist, and experimental methods, especially in relation to urban development plans, are subject to certain shortcomings that are given below:

- Failure to consider temporal and spatial scale effects in urban development plans;

- Absence of appropriate indicators with an effective scale for urban development plans;

- Lack of systematic consideration of the environmental effects;

- Absence of transparent and effective output for urban decision-makers;

- Failure to recognize the type of environmental impacts (primary and secondary effects) and, consequently, the inability of developing corrective measures [4-10].

The possibility of conducting EIA based on the resilient development mindset was proposed in the International Association for Impact Assessment (IAIA) conference held in Puebla, Mexico, 2010 [11,12]. "Resilience" is the capacity of an ecosystem to recover to its natural state in the face of changes and/or humanled exploitation [13]. An alternative definition of "resilience" is the capacity of socio-ecological systems to absorb disturbances while maintaining the inherent system functions, structures, and performances [14].

The resilience mindset provides an insight into the unpredictable future, the inevitability of change, and vulnerability of socio-ecological systems [15]. Key concepts of resilience mindset such as multiple spatial and temporal scales (panarchy), appropriate temporal and spatial scales (adaptive cycle), interdependence between human and nature (socio-ecological system), and post-assessment measures for monitoring and public participation (adaptive governance) improve different dimensions of the environmental assessment process $[11,12,16]$. In particular, resilience mindset is a structured method that emphasizes potential complications, uncertainties, ecological risks [15], systems' internal relations, and processes $[13,16]$. These characteristics of resilient development can facilitate the identification of environmental impacts. In Table 1 , the key concepts of resilience mindset in EIA are listed.

Nowadays, cities are considered as socio-ecological

Table 1. Significance of the application of resilience concepts in Environmental Impact Assessment (EIA).

\begin{tabular}{|c|c|}
\hline $\begin{array}{l}\text { Concepts of } \\
\text { resilience mindset }\end{array}$ & $\begin{array}{l}\text { Significance of the application } \\
\text { of resilience concepts in EIA }\end{array}$ \\
\hline Socio-ecological systems & $\begin{array}{l}\text { Looking at the system as a whole in EIA. } \\
\text { Not seeing the system as separate parts. } \\
\text { Understanding the relationship between social and ecological systems. } \\
\text { Emphasis on multidisciplinary studies of assessment. }\end{array}$ \\
\hline Adaptive cycle & $\begin{array}{l}\text { Awareness and knowledge about the type and the right timing for management. } \\
\text { Decrease in Uncertainty of the assessment. }\end{array}$ \\
\hline Panarchy & $\begin{array}{l}\text { Choosing the appropriate temporal and spatial scales for assessment. } \\
\text { Finding an incongruous and heterogeneous solution in relation to different tiers } \\
\text { of decision-making interaction between different tiers. } \\
\text { Not putting any limit on assessment process in official occasions and time scales } \\
\text { of the suggested plan. } \\
\text { Attention to trends and future threats concerns the ability of prediction on the } \\
\text { basis of current information. }\end{array}$ \\
\hline Adaptive governance & $\begin{array}{l}\text { Clearance. } \\
\text { Cooperative learning. } \\
\text { Cooperation at national, regional, and local levels. } \\
\text { Adapting the management sections on ecological scales of the alleged sources. } \\
\text { Using experiences from the past and requires the capacity to utilize the necessary } \\
\text { knowledge to deal with similar conditions in the future. }\end{array}$ \\
\hline
\end{tabular}


systems [17,18]. Urban environments are facing increasing environmental, economic, and social problems that endanger their resilience and sustainability as well as the comfort of their residents [19]. Cities are influenced by human activities on different temporal and spatial scales. Assessing the environmental impacts of urban development policies under the resilience mindset and understanding the interactions between urban structural changes and functions are important [17,19-23]. Urban resilience has five main dimensions: natural, economic, social, physical, and institutional. Urban resilience also pursues the following four goals: resisting, recovering, adapting, and transforming $[24,25]$. Therefore, the resilience mindset can be used to enhance EIA, especially in urban projects.

In the last decades, high-rise construction has been accepted as an urban development strategy in many megacities due to the scarcity of land. Highrise buildings impose positive and negative impacts on urban environments by reducing land occupation and urban impervious surfaces, as well as changing the natural pattern of wind flow. Protection of pervious surfaces in urban areas is important for decreasing the storm flow and flood frequency. In addition, the environmental impact of high-rise buildings on wind flow patterns is essential for establishing strategies to ensure sustainable urban development.

In recent years, many studies related to simulation of airflow around buildings have been performed. The results of these studies showed the significant impact of high-rise buildings on the airflow patterns and, also, the accumulation of air pollutants around buildings [2427]. In a study conducted by Yuan et al., the relationship between effective factors in urban built environments with high-density high-rise building areas and noise pollution was examined. Based on the results of this study, controlling the spatial distribution of residential buildings, the larger proportion of buildings coverage, and the complex shape of buildings were effective factors in reducing noise pollution levels and, thus, maintaining the sustainability of the urban environment [28]. In another study, the effects of highrise buildings in Moscow were evaluated. In this study, the effects of high-rise buildings and the height of the buildings on local climate (variations in temperature and wind speeds) were investigated. Furthermore, this paper emphasized that high-rise buildings played an important role in creating urban heat islands. The density of buildings also exacerbates air pollution and local climate change [29]. Due to these important impacts, in the planning and design of high-rise buildings, the configurations and locations of tall buildings must be considered.

In the current study, an example of environmental impact with the resilient development mindset is pre- sented. According to the meteorological station report in 2015, the speeds of westerly and northerly winds have been on the decline in Tehran over the past 60 years [30]. This report argued that one of the causes of reduced wind speed was the inappropriate placement of high-rise buildings. In recent years, District 22 in northwest Tehran has experienced significant growth in the construction of high-rise buildings. Considering that District 22 is located at the inlet air corridor of Tehran stretching along the dominant wind direction, studying the effects of high-rise buildings on the wind flow pattern is important and needs to be assessed. In the present study, the resilience mindset is used to examine two important environmental effects of highrise buildings, namely changing the natural pattern of wind flow and protecting the urban pervious surface in District 22 of Tehran.

\section{Method and analysis}

\subsection{Data collection and processing}

The case study region is District 22 of Tehran, Iran, which is located in the northwest part of the city, as shown in Figure 1.

The population of the city of Tehran was 8.6 million in 2016 and sustained an average annual growth rate of $1.29 \%$ [31]. It is important to note that $2.02 \%$ of the population of Tehran inhabits in District 22. Based on the Statistics and Informatics Report of the Planning Department of Tehran Municipality Office, the construction trend of high-rise buildings in District 22 increased by $103 \%$ over the years 2004-2014 [32].

In this study, the environmental assessment of high-rise buildings is conducted based on the resilience mindset. Figure 2 shows the conceptual framework of EIA developed in this research. The resilience mindset is focused on the relationship between structure and function in the focal system. Accordingly, structural and physical changes over the course of a lifetime of high-rise buildings are important. Changes in the ecosystem structure alter ecological function. Therefore, to determine the environmental impacts of highrise buildings, this study must respond to the following questions:

- What changes in land cover are caused by the construction of a high-rise building?

- Which of the ecological functions of the city is affected by changes in an urban land cover?

- What are the primary and secondary effects of the changes in urban ecological functions?

\subsection{Impervious surfaces analysis}

In order to evaluate the changes in impervious surfaces, Google Earth Landsat satellite images [33] of District 22 for the period 2004-2014 were used, and the 


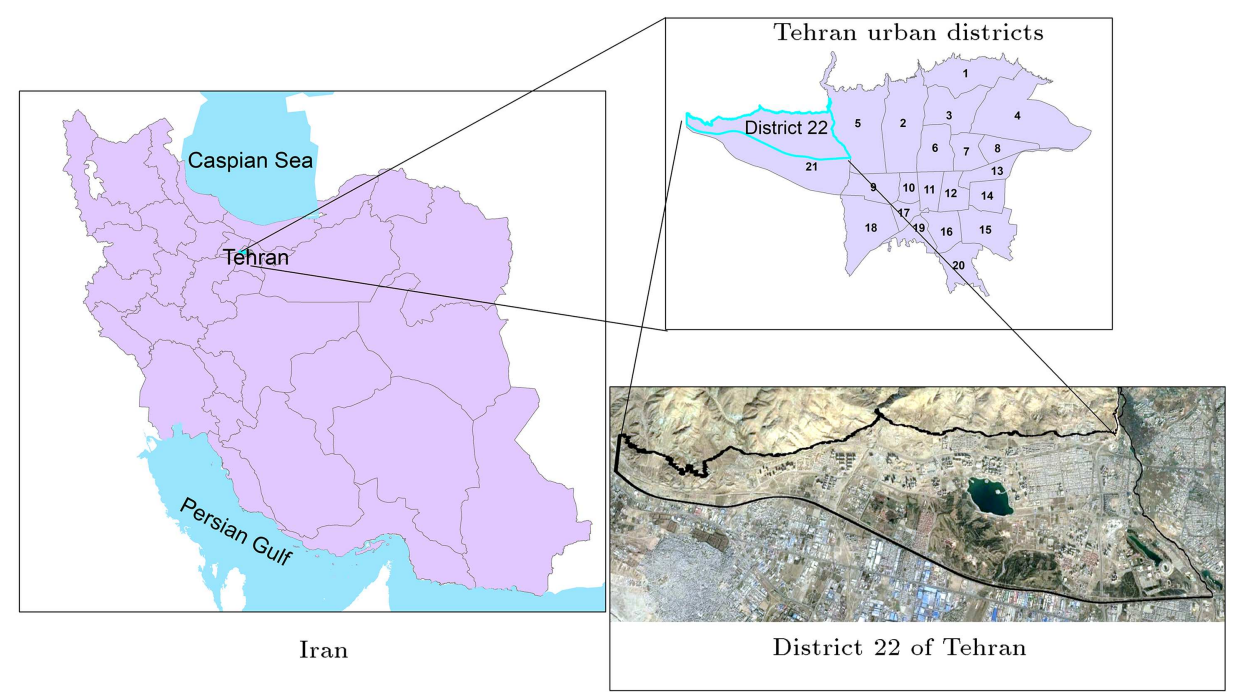

Figure 1. Location of District 22 of Tehran.

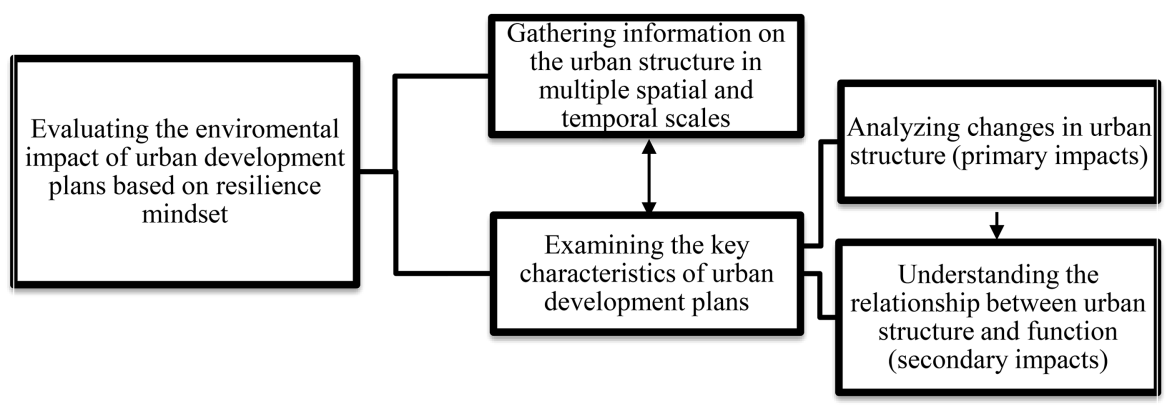

Figure 2. The conceptual framework of environmental impact assessment based on the resilience mindset.

land cover maps were prepared. Then, the coverage of both impervious and pervious surfaces was evaluated based on field observations and GIS software, and the corresponding impacts of high-rise buildings were estimated. Here, pervious surfaces include urban green space (parks), gardens, trees on street margins as well as those inside houses, forest parks, farms, canals, wastelands, and children's playgrounds. Passageways, buildings, and constructions determined the impervious surfaces. The findings are described in the subsequent sections.

\subsection{Wind flow analysis}

For the wind flow analysis, three high-rise building layout configurations in District 22 of Tehran were selected. For each configuration, the formation and distribution of wind flow around the buildings were simulated using the ENVI-met free software [34]. The software uses a microclimate model for the 3D analysis of the wind airflow fields. The entire computational domain was meshed, and the Reynolds Averaged NavierStokes (RANS) equations in conjunction with the $k-\varepsilon$ turbulence model equations were solved. The boundary conditions for the simulation were set to $6 \mathrm{~m} / \mathrm{s}$ westerly wind, based on local meteorological data. The corresponding velocity, pressure, and turbulence properties of the wind flow field were evaluated.

\subsection{Configuration of high-rise buildings in the case study area}

Figure 3 shows the configuration of high-rise buildings in District 22. The map was prepared using both satellite images and field surveys. As shown in Figure 3, most of the high-rise buildings in District 22 are located in the eastern parts of the area at an altitude of 1280 to $1390 \mathrm{~m}$ around Chitgar Lake.

\subsection{Impact of high-rise buildings on impervious surfaces}

The comparison of the map of the area shows that growth in construction resulted in a marked increase in the impervious surface area in District 22, rising from $32 \%$ in 2004 to $50.45 \%$ in 2014 . Table 2 shows the statistics of the historical population, construction permits, and growth of the impervious surface area in District 22 up to year 2022 (as illustrated in Table 2, the statistics from the year 2004 to 2014 was 


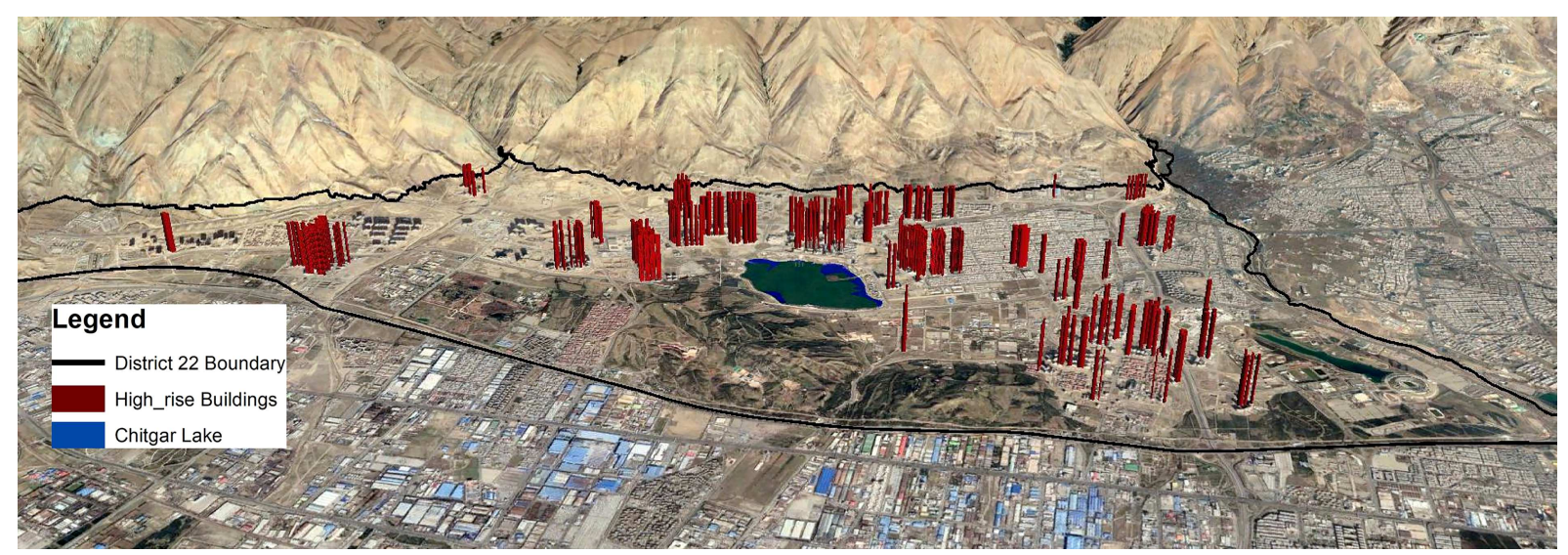

Figure 3. Configuration of high-rise buildings in the case study area.

Table 2. Population, construction permits, and impervious surface variations in District 22 for the period 2004-2020.

\begin{tabular}{|c|c|c|c|c|c|c|c|c|c|c|}
\hline & \multicolumn{10}{|c|}{ Year } \\
\hline & 2004 & 2006 & 2008 & 2010 & 2012 & 2014 & 2016 & 2018 & 2020 & 2022 \\
\hline Population & 98303 & 108674 & 112369 & 120140 & 128958 & 138095 & 147411 & 157730 & 168771 & 180584 \\
\hline $\begin{array}{l}\text { Total number of } \\
\text { building permits }\end{array}$ & 306 & 157 & 410 & 448 & 626 & 593 & 1200 & 1578 & 2014 & 2514 \\
\hline $\begin{array}{l}\text { The number of } \\
\text { less-than 10-story } \\
\text { building permits }\end{array}$ & 280 & 138 & 380 & 413 & 582 & 540 & 1123 & 1479 & 1889 & 2360 \\
\hline $\begin{array}{l}\text { The number of } \\
\text { more-than 10-story } \\
\text { building permits }\end{array}$ & 26 & 19 & 30 & 35 & 44 & 53 & 77 & 99 & 125 & 154 \\
\hline $\begin{array}{l}\text { Impervious surface } \\
\text { area (ha) }\end{array}$ & 1989 & 2015 & 2134 & 2415 & 2805 & 3128 & 3974 & 4748 & 5652 & 6682 \\
\hline
\end{tabular}

officially published by the municipality of Tehran and the statistics from the year 2016 to 2022 is projected). By determining the number of construction permits for high-rise and low-rise buildings along with the corresponding areas of impervious surfaces, the rate of their changes was estimated using Trend Analysis Method. In order to study the trend of the growth of impervious surfaces with constructions, the number of permits for high-rise and low-rise buildings is plotted versus the percentages of impervious surfaces in District 22 in Figure 4 using the Mini Tab software. It should be pointed out that District 22 is relatively new and historical data on population and building and impervious area growth are quite limited. In addition, the Mini Tab Software was used for generating the data on impervious surface coverage more than $50 \%$.

Table 2 and Figure 4 show that there are marked increases in construction and impervious surface areas in District 22. In particular, sharper increases were seen between 2006 and 2014, that are predicted to continue in the future due to the construction of recreational centers in the district, including the major construction of a lake (Shohadaye Khalij Fars (Chitgar) Lake). It is also seen that as the number of building permits increases, the number of both high-rise and low-rise buildings grows (until 2022). In the years when the construction increase is more rapid, the rate of increase of impervious surface growth is equally more intense. In general, there is a positive correlation coefficient of 0.95 between the number of high-rise building permits and the impervious surfaces as well as between the number of permits for buildings with less than 10 floors and impervious surfaces.

Figure 5 shows the relationships between high- 

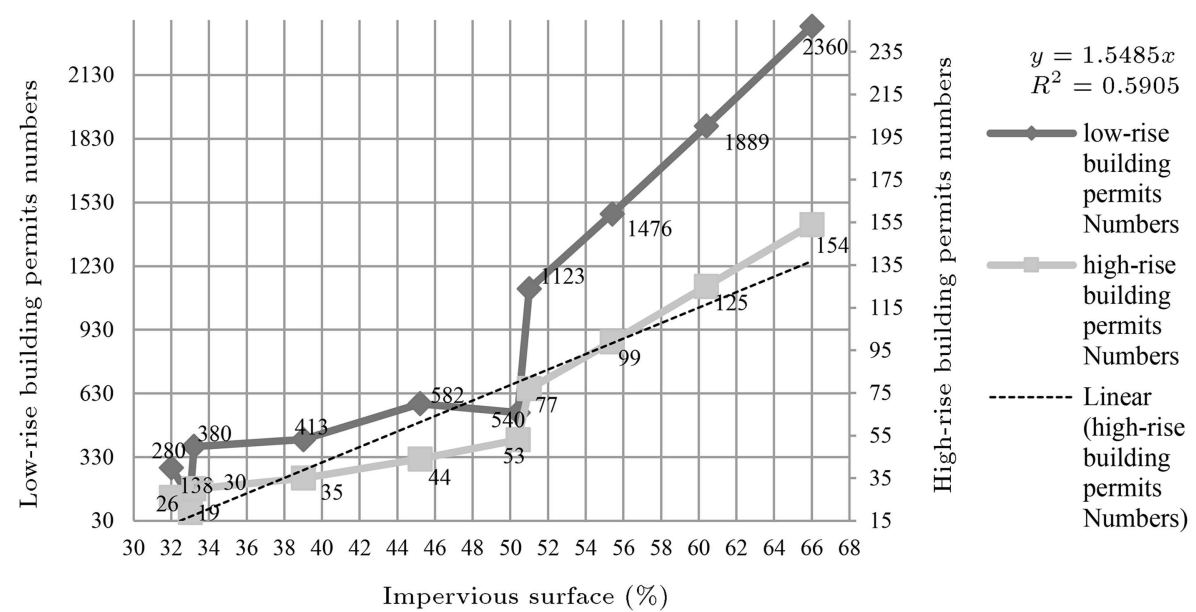

Figure 4. Variations of the percentage of impervious surfaces with the number of permits for high-rise and low-rise buildings.

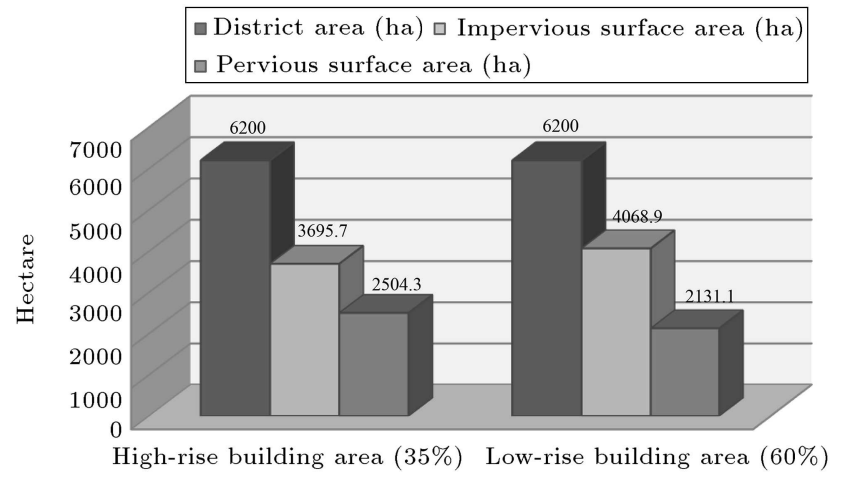

Figure 5. Relationship between high-rise and low-rise buildings with urban pervious and impervious surfaces.

rise and low-rise buildings and urban pervious and impervious surfaces. According to the Tehran comprehensive plan, building codes, the occupied areas by buildings with less than 10 floors, are up to $65 \%$ of the land; in addition, for buildings that have more than 10 stories, the maximum coverage is $35 \%$. According to the estimated population growth rate, by 2022 , there will be a need for additional 22089 residential units in District 22. If these residential units are constructed in buildings that have less than 10 floors (assuming that all buildings have 5 floors), then 2209 buildings must be constructed that occupy 941 hectares of District 22 . If the constructed buildings have more than 10 floors (assuming all are of 15 floors), then 736 buildings occupying 568 hectares of the region are needed. According to these estimates, the construction of high-rise buildings would preserve the urban pervious surfaces by 373 hectares.

\subsection{Impact of high-rise buildings on wind airflow}

In this section, three combinations of high-rise building configurations in District 22 of Tehran are studied.

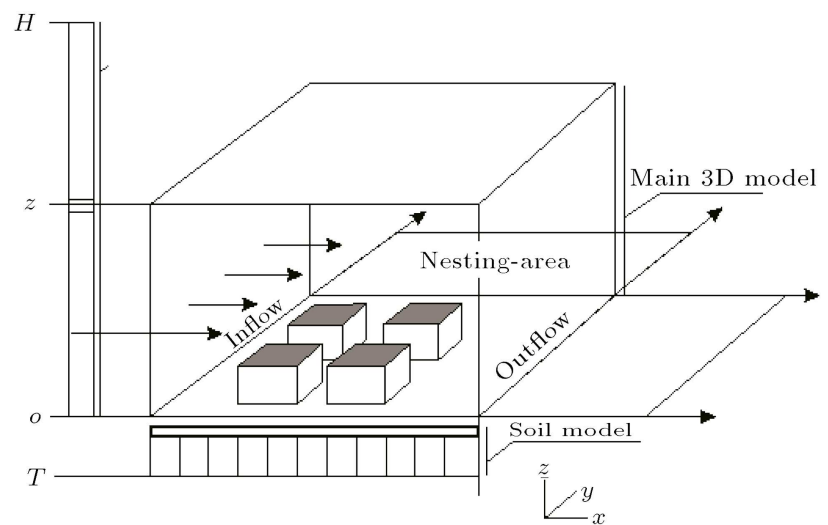

Figure 6. Schematic of the $3 \mathrm{D}$ solution domain and the associated boundary conditions (Ref: www.envi-met.net).

For each group, the distributions of wind flow around the buildings are simulated. The wind velocity contours are evaluated to show wind flow patterns and the formation of recirculating regions downstream of buildings. Instead of showing the velocity vectors or streamlines, fluid particle locations at the consecutive time are shown as black dots. Thus, these black dots are aggregated in regions with low wind speeds and spread out in the high wind speed areas. Aligned particles show the fluid particle path through the region. The continuous trajectories are not plotted to avoid crowding the figures.

To simulate microclimate models, it is necessary to consider a wide solution domain to provide an accurate and realistic condition for flow around the models. However, since the domain is already quite large, the use of a wider region was not possible. In this paper, a 3D computation domain, shown schematically in Figure 6, was used and all model variables at the inflow boundary were specified.

For the simulation study, the vertical profiles of mean flow velocity, turbulence kinetic energy $k$, and 
Table 3. Computational mesh used for different cases.

\begin{tabular}{cccc}
\hline & \multicolumn{3}{c}{ Groups } \\
\cline { 2 - 4 } & G1 & G2 & G3 \\
\hline Meshing quantity & $150 \times 150 \times 35$ & $100 \times 100 \times 40$ & $100 \times 100 \times 40$ \\
$\Delta \boldsymbol{x}$ & $1.5 \mathrm{~m}$ & $3 \mathrm{~m}$ & $1 \mathrm{~m}$ \\
$\boldsymbol{\Delta} \boldsymbol{y}$ & $1.5 \mathrm{~m}$ & $3 \mathrm{~m}$ & $1 \mathrm{~m}$ \\
$\boldsymbol{\Delta} \boldsymbol{z}$ & $1.6 \mathrm{~m}$ & $1.6 \mathrm{~m}$ & $1.6 \mathrm{~m}$ \\
\hline
\end{tabular}

dissipation rates $\varepsilon$ were specified at the inflow boundary, as showed in Figure 6. No-slip boundary condition is used for all solid surfaces. The inflow velocity profile was obtained from the power-law profile, and a zero-gradient boundary condition was imposed on the outflow and lateral boundaries. At the top boundary, a symmetry boundary condition was used.

On all solid surfaces, $k$ and $\varepsilon$ represent the functions of local tangential friction velocity, $u^{*}$, evaluated using the flow components tangential to the surface. That is:

$$
\begin{aligned}
& k_{w}=\frac{u^{* 2}}{\sqrt{c_{\mu}}}, \\
& \varepsilon_{w}=\frac{u^{* 3}}{\kappa z_{o}},
\end{aligned}
$$

where $\kappa(=0.4)$ is the von Kármán constant, and $z_{o}$ is the microscale roughness length of the surface.

By using open lateral boundary conditions, the values of the next grid point close to the border are copied to the border for each time step. The mesh convergence analysis was performed. The final meshes used for various cases are shown in Table 3 . Since the computational domains are quite large, the cell sizes are also large enough to make the computational effort manageable.

\subsubsection{First combination of high-rise buildings}

In this section, two high-rise buildings with approximately the same dimensions and height of about $45 \mathrm{~m}$ that are next to each other in a row are considered. Figure 7 schematically shows the configuration of two high-rise buildings and their dimension in the $x y$-plane. Here, the buildings are $8 \mathrm{~m}$ apart. The wind is typically blowing from the west at $6 \mathrm{~m} / \mathrm{s}$.

Many of the high-rise buildings in District 22 were built as pairs next to each other. In fact, a side-byside layout of high-rise buildings is the most common combination in this area.

The simulation results of the velocity magnitude contours on a vertical $x z$-plane at $y=45 \mathrm{~m}$ are shown in Figure 8. It was found that as the wind interacted with the first building, it accelerated. As a result, the wind speed increased on the top of the building and its maximum values were seen near the left

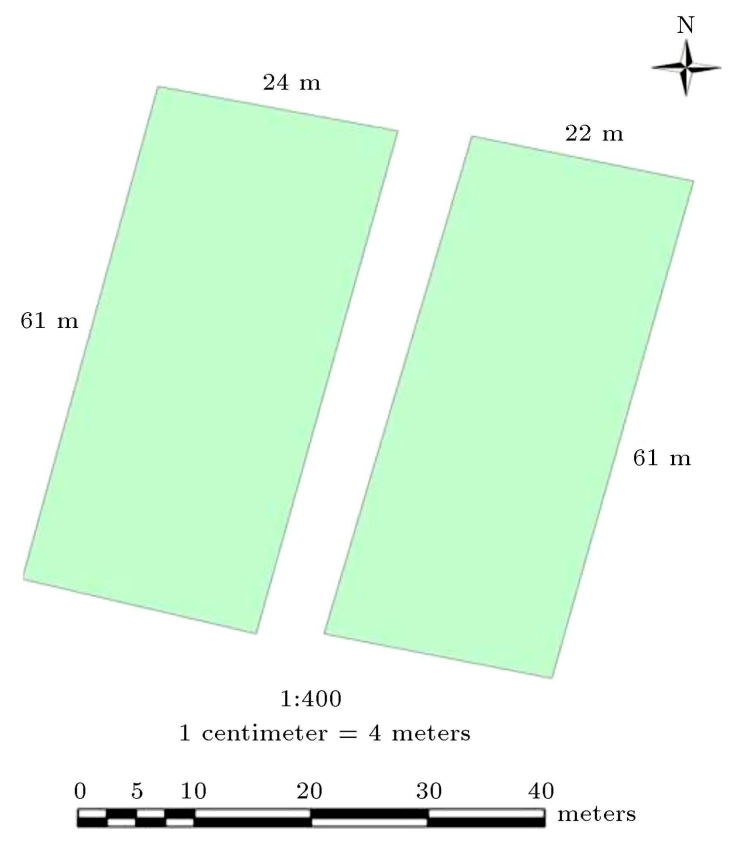

Figure 7. Schematic of the first configuration of two high-rise buildings side-by-side.

corner of the building and over its top. In addition, a large recirculation region on the backside of the second building forms. It is also seen that the wind speed between the two buildings is quite low due to the short distance of the gap.

Figure 9 shows the velocity magnitude contours on a horizontal $x y$-plane at $z=6 \mathrm{~m}$. It is seen that the wind speed on the side of the building increases due to the blockage. On the backside of the second building, two counter-rotating recirculation regions form. This indicates that the recirculation regions on the back of the building have rather complex $3 \mathrm{D}$ structures. It is also seen that the flow around the building pairs is not symmetrical. This is because the buildings are not aligned with the wind flow direction (coming from the west).

\subsubsection{Second combination of high-rise and low-rise buildings}

In this section, the wind flow around combinations of a high-rise building adjacent to a low-rise building is studied. It is assumed that the heights of high-rise and low-rise buildings are $120 \mathrm{~m}$ and $30 \mathrm{~m}$, respectively. 


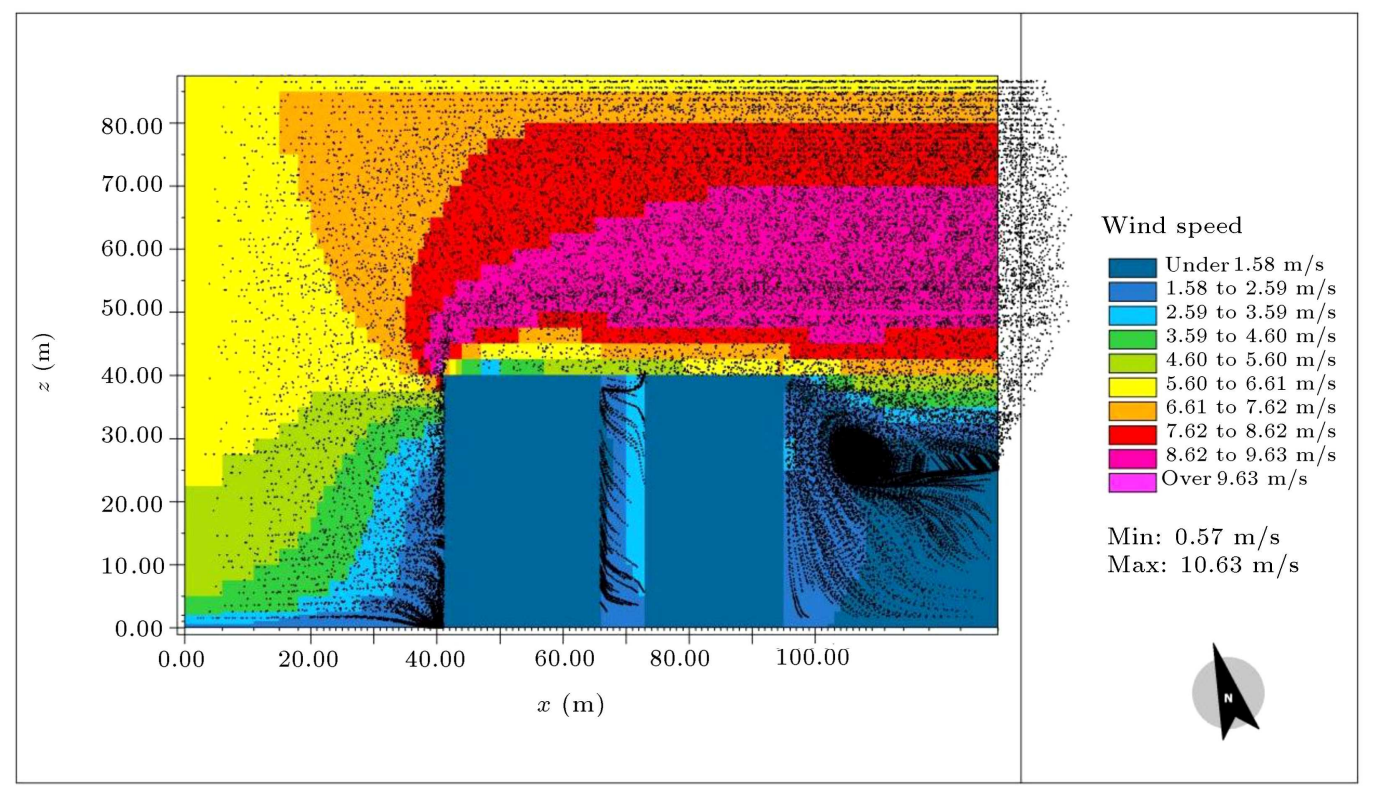

Figure 8. Wind speed contours on a vertical plane at $y=45 \mathrm{~m}$ across a pair of high-rise buildings. Inlet wind speed $=5 \mathrm{~m} / \mathrm{s}$ at a height of $10 \mathrm{~m}$ from the ground.

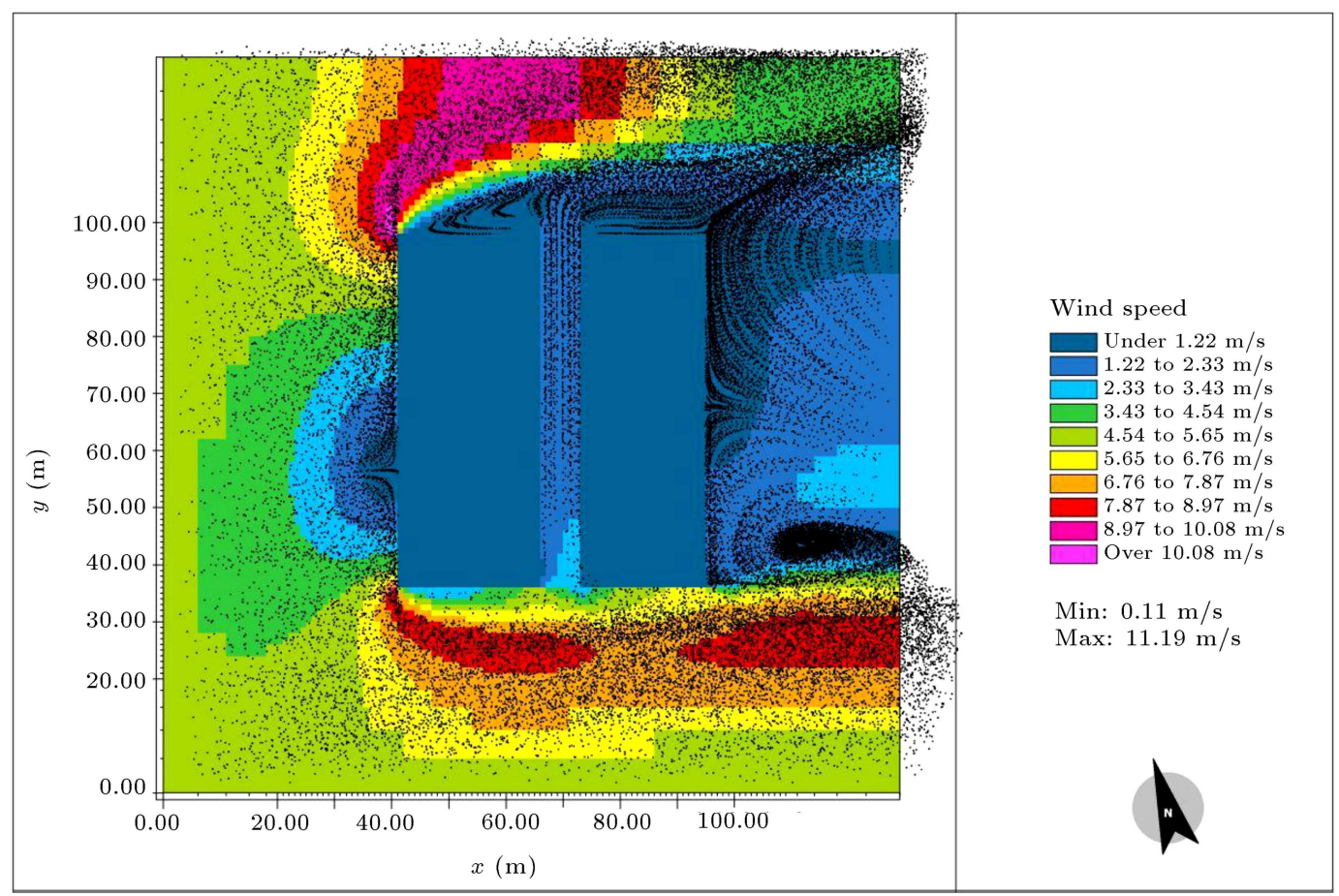

Figure 9. Wind speed contours on a horizontal plane at $z=6 \mathrm{~m}$ across a pair of high-rise buildings. Inlet wind speed $=5 \mathrm{~m} / \mathrm{s}$.

Figure 10 schematically shows the configuration of high-rise and low-rise buildings and their dimensions on the horizontal $x y$-plane. Herein, the buildings are 8 $\mathrm{m}$ apart. The wind blows from the west at $5 \mathrm{~m} / \mathrm{s}$.

The simulation results of the wind velocity magnitude contours are described in this section. The velocity magnitude contours on a vertical $x z$-plane at $y=150 \mathrm{~m}$ are shown in Figure 11. It is seen that the wind speed on the top of the high-rise building increases. In addition, a large recirculation region on the backside of the high-rise building forms, which engulfs the low-rise building completely.

Figure 12 shows the velocity magnitude contours on a horizontal $x y$-plane at $z=24 \mathrm{~m}$. It is seen 


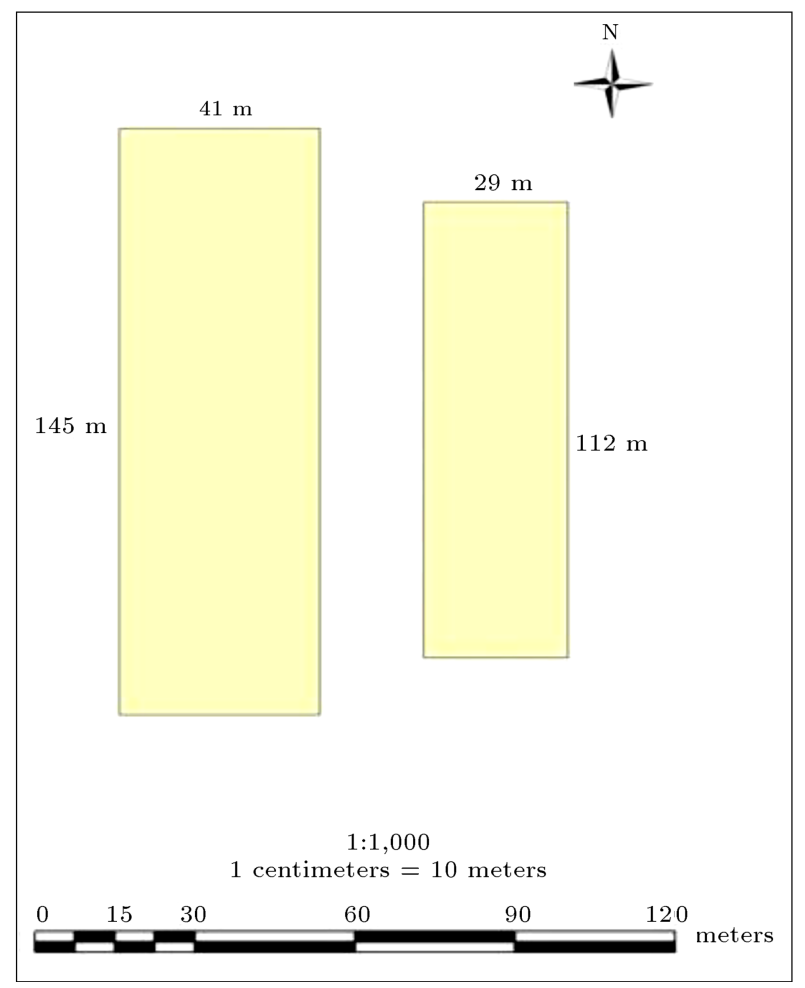

Figure 10. Schematic of the second configuration of high-rise and low-rise buildings.

that the wind speed increases on the upstream sides of the high-rise buildings similar to the first combination of buildings. On the backside of the high-rise building, two counter-rotating recirculation regions form, because the downstream building is of lower width than the upstream taller building. This allows the formation of the vortices behind the upstream building that penetrate partly into the region between the two buildings. However, in the mid-region between the two buildings, the wind velocity is quite low. It is also seen that the flow around the building pairs is roughly symmetrical as the wind flow is nearly perpendicular to the buildings.

Figures 13 and 14 show the normalized turbulence kinetic energy contours on a vertical $x z$-plane at $y=$ $150 \mathrm{~m}$ and a horizontal $x y$-plane at $z=24 \mathrm{~m}$, respectively. It is seen that the turbulence intensity is the highest near the edges of the taller upstream building. This is due to flow separation and intense mixing at the shear layer in these regions. Since the wind flow passes the buildings, the turbulence of wind velocity decreases and, finally, reaches its minimum value.

\subsubsection{Third group of high-rise buildings}

Wind flows around the third group of high-rise buildings are studied in this section. In this group, twelve high-rise buildings with the same heights of $40 \mathrm{~m}$ in close proximity, as shown schematically in Figure 15, are considered. The wind blows from the west at $5 \mathrm{~m} / \mathrm{s}$.

Figure 16 shows the velocity magnitude contours on a horizontal $x y$-plane at $z=30 \mathrm{~m}$ across the third group of twelve high-rise buildings. It is seen that the wind speed increases on the sides of high-rise buildings. For the third group of buildings, the distances between

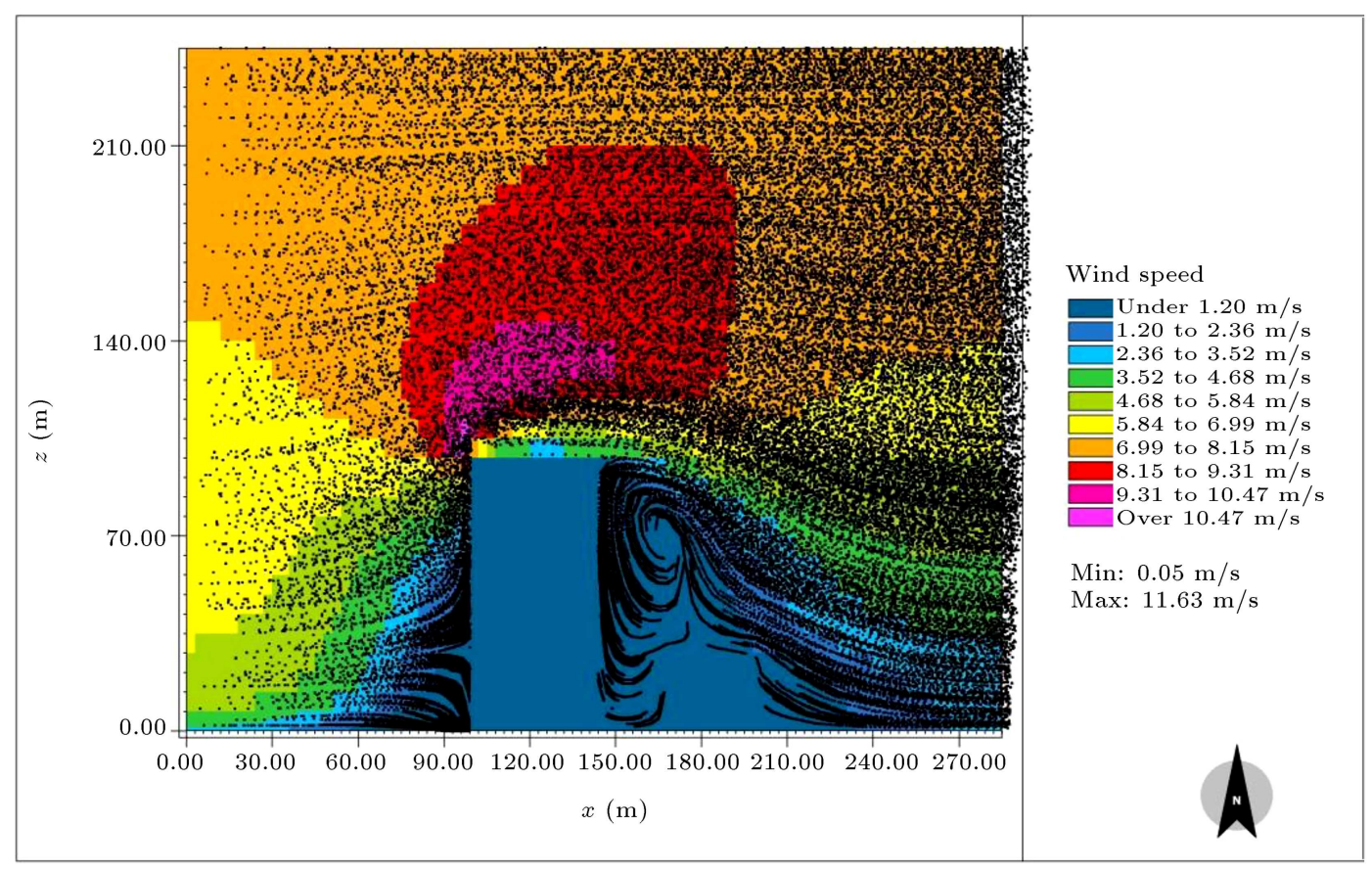

Figure 11. Wind velocity magnitude contours on a vertical section at $y=150 \mathrm{~m}$ across the second combination of buildings. Inlet wind speed is $5 \mathrm{~m} / \mathrm{s}$ at a height of $10 \mathrm{~m}$ from the ground. 


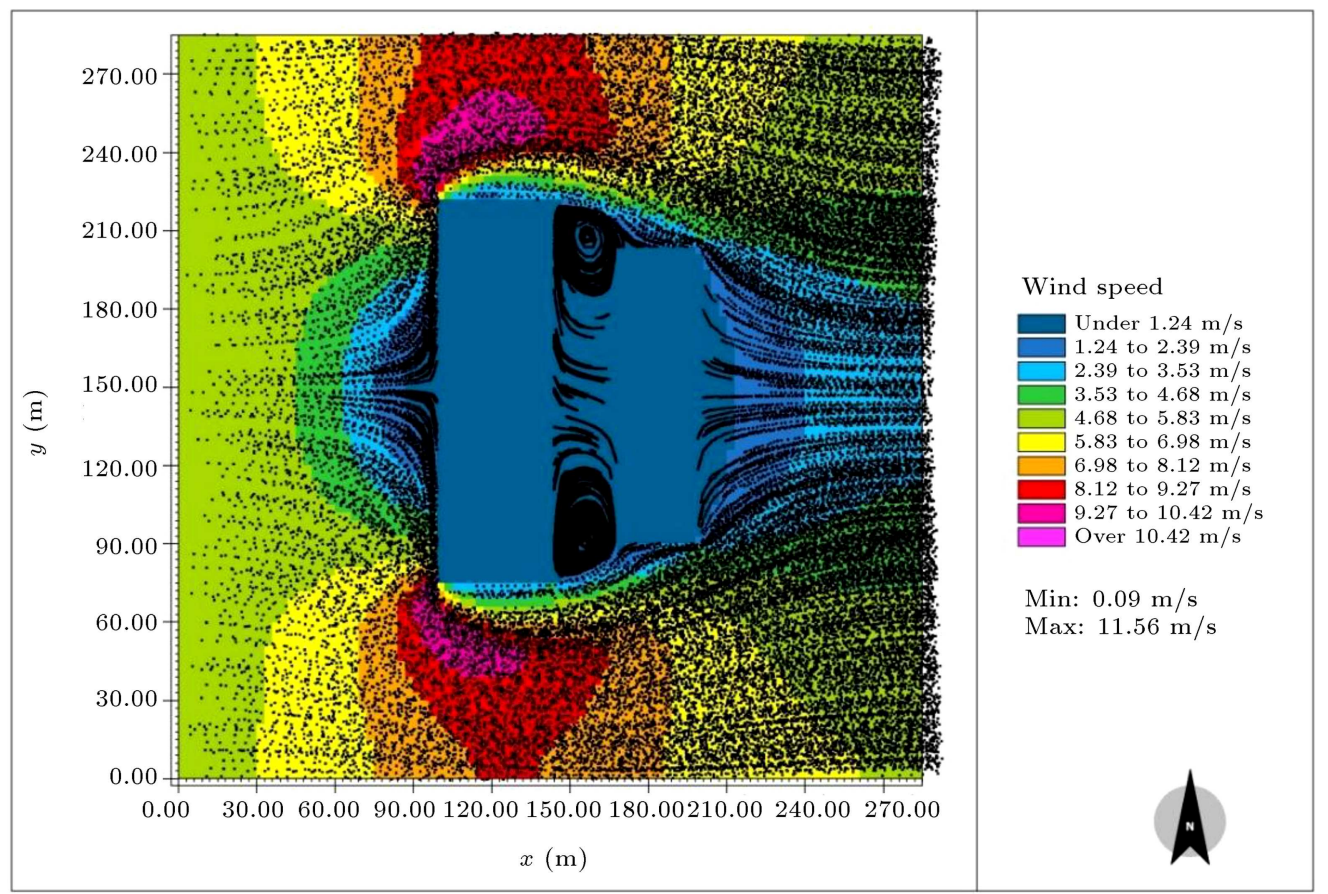

Figure 12. Wind speed contours on a horizontal section at $z=24 \mathrm{~m}$ across a pair of high-rise and low-rise buildings. Inlet wind speed $=5 \mathrm{~m} / \mathrm{s}$.

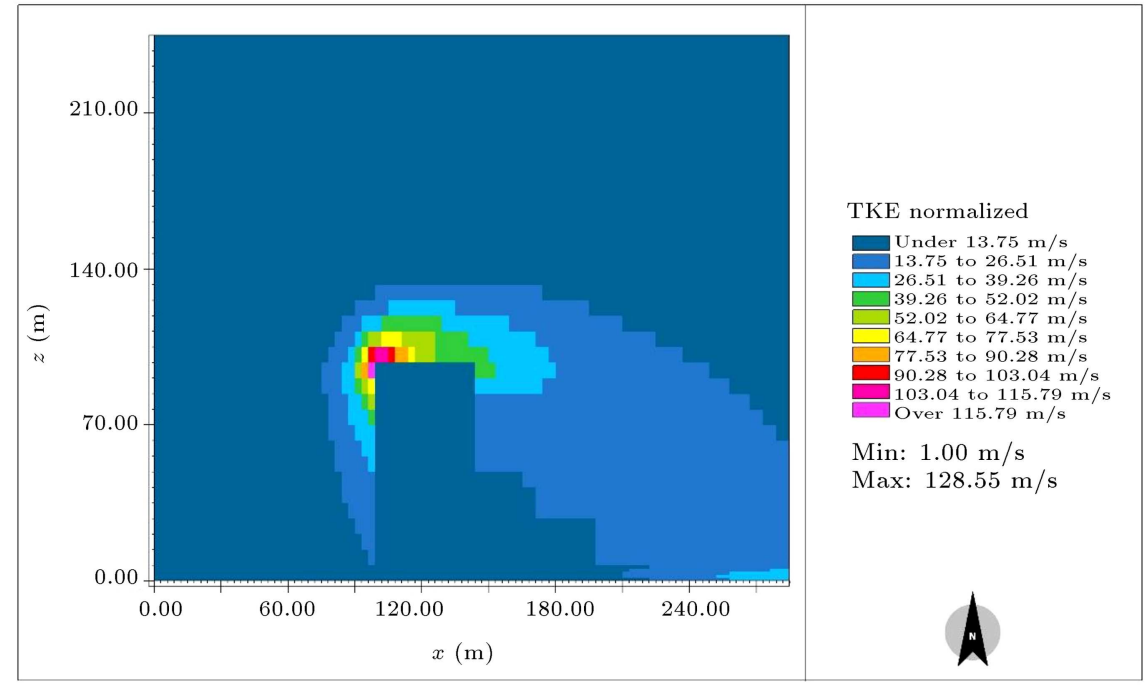

Figure 13. Normalized turbulence kinetic energy contours on a vertical section at $y=150 \mathrm{~m}$ across the second combination of buildings.

the buildings are relatively longer than the first and second groups. This causes the formation of channeling of air between the buildings and generation of highspeed winds clearly seen for the upstream buildings in Figure 16. Behind the buildings, the formation of recirculation regions can be seen in this figure. The buildings downstream are in the wake of upstream buildings and are exposed to lower wind speeds.

Figure 17 shows the turbulence kinetic energy contours on a horizontal plane $z=6 \mathrm{~m}$ across the third group of buildings. It is seen that the peak turbulence fluctuations occur near the wall and at the corner of the buildings. The intensity of the normalized turbulence kinetic energy is noticeably higher for the downstream buildings because of the lower mean wind velocity near the downstream buildings.

\section{Discussions}

As noted previously, the environmental assessment based on the resilient development mindset through the study of the interaction between structure and 


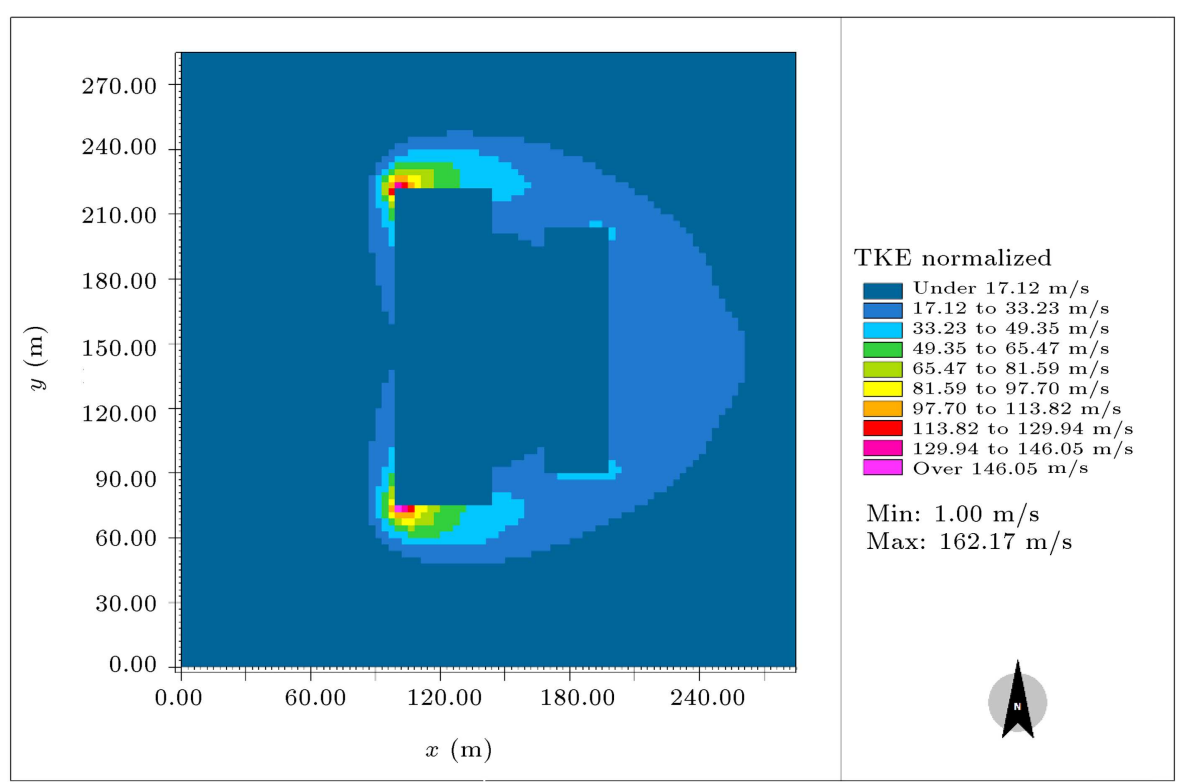

Figure 14. Normalized turbulence kinetic energy contours on a horizontal section at $z=24 \mathrm{~m}$ across the second combination of buildings.

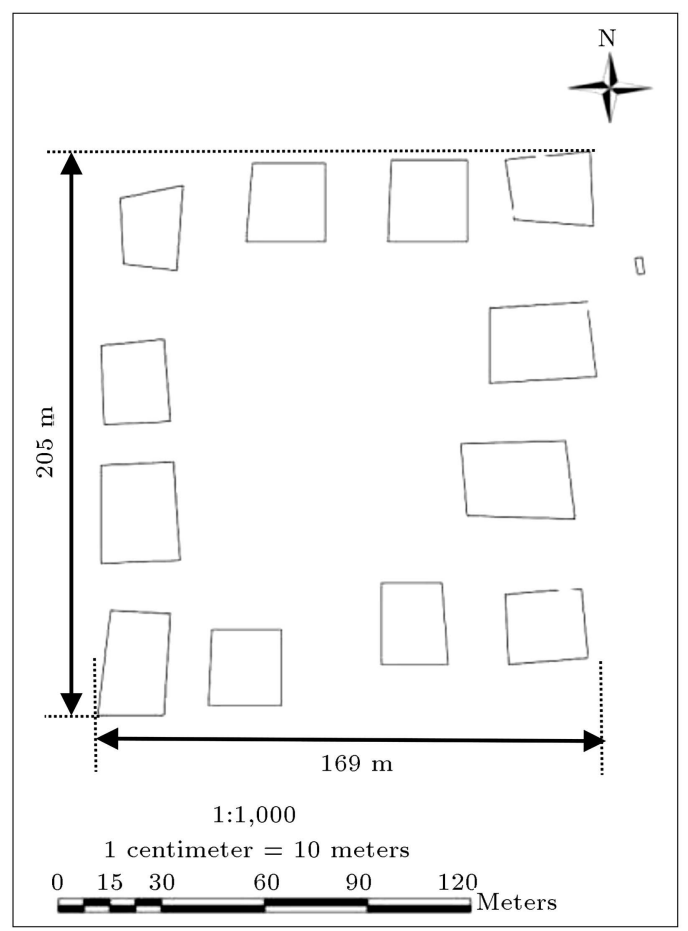

Figure 15. Schematics of the third group of twelve high-rise buildings.

function provides the ability to understand the nature of different primary and secondary impacts. Any kind of change in the structure of the land caused by development and construction is known as the primary impact. Secondary impacts typically follow the primary impacts (with delay) that create a disturbance in some vital functions of an ecosystem. Understanding the type of impacts is important for environmental planning or policy making. With respect to the dynamic condition of ecosystem functions such as water and air, control of secondary impacts is typically costly and difficult.

\subsection{Environmental assessment of high-rise building on impervious surfaces}

District 22 in Tehran municipality has experienced an annual population growth of $4.1 \%$ in the last 35 years. Furthermore, during 2003-2013, the number of construction permits increased by about $1.82 \%$ per year, with about 7 to $9 \%$ of high-rise buildings. In Figure 18, the impacts of high-rise buildings on the conservation of pervious surfaces based on primary and secondary effects are shown.

As shown in this figure, construction in District 22 changes the land cover and causes an increase in impermeable surfaces (change in structure). Following the reduction of permeable urban surface, changes occur in ecosystem functions involving water (flood, decreased groundwater recharge, and hydrological cycle) and air (heat island effect). There is a direct relationship between high-rise buildings and maintenance of pervious surfaces, and high-rise buildings in District 22 preserved 373.2 hectares of pervious surfaces that helped sustain the urban development in this district.

\subsection{EIA of high-rise building on wind flow}

The high-rise buildings in District 22 of Tehran include three different groups. The results of this study show that the following factors influence the quality of urban wind flow:

1. Initial wind direction;

2. Building height and dimensions; 


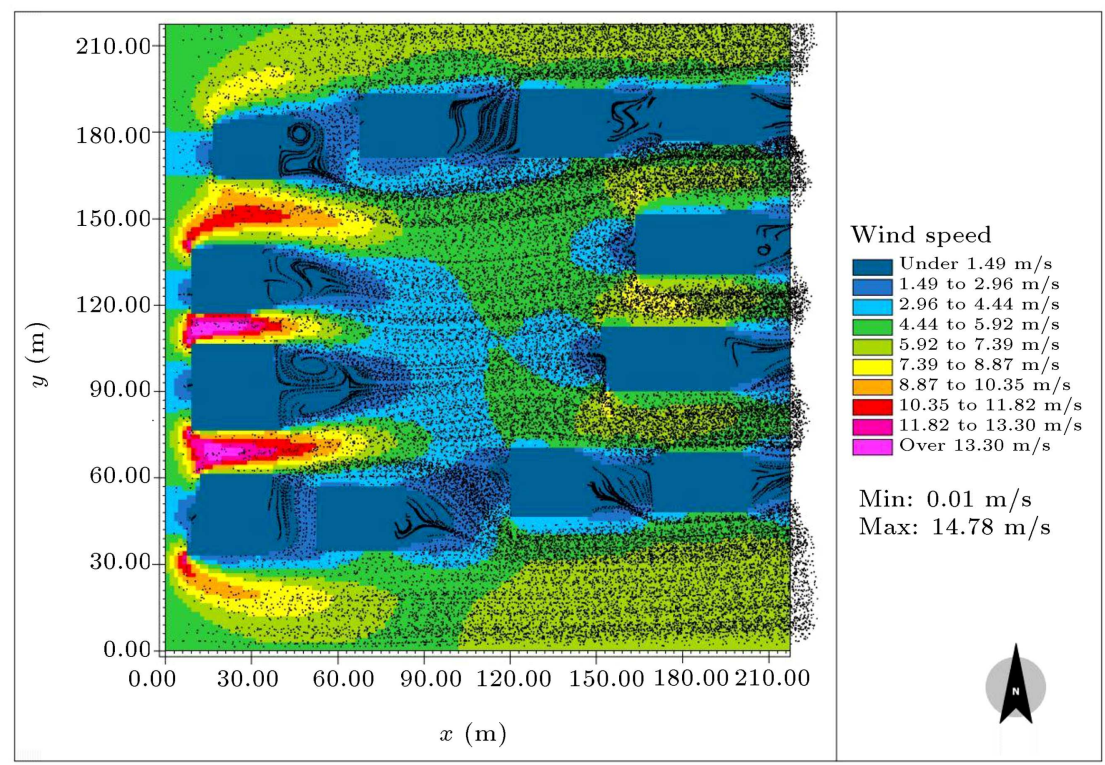

Figure 16. Wind speed contours on a horizontal plane at $z=6 \mathrm{~m}$ across the third group of high-rise buildings. Inlet wind speed $=5 \mathrm{~m} / \mathrm{s}$.

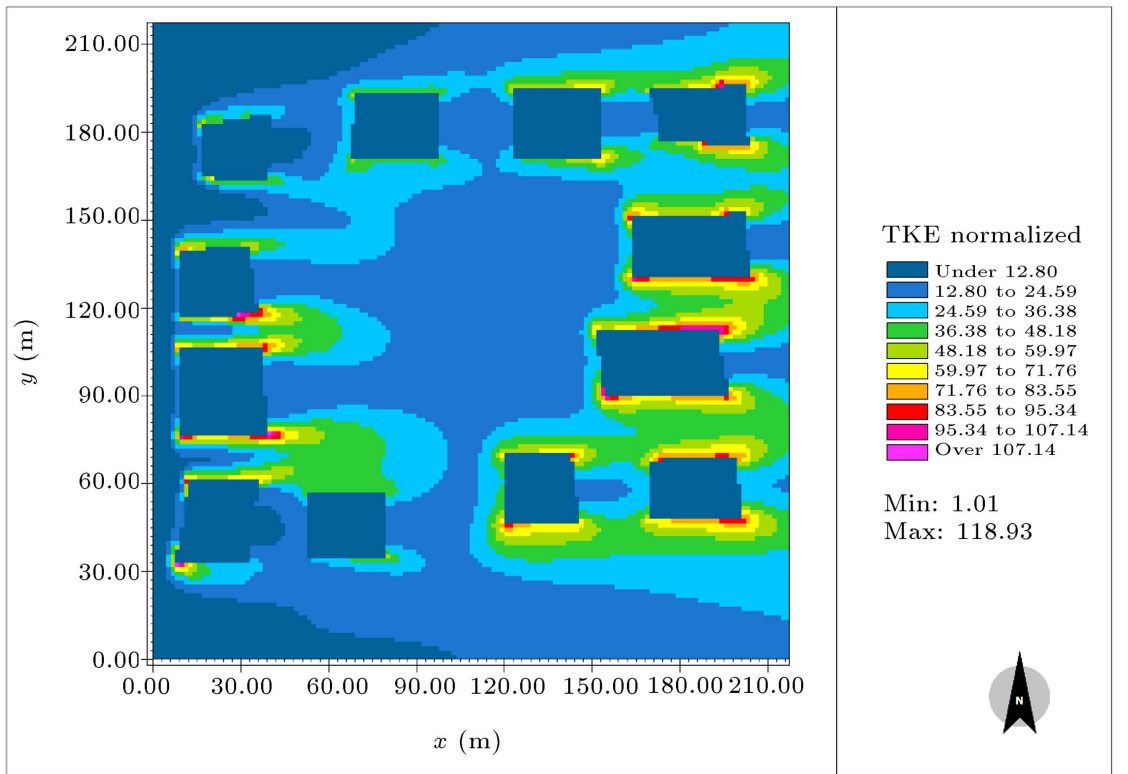

Figure 17. Normalized turbulent kinetic energy contours on a horizontal plane at $z=6 \mathrm{~m}$ across the third group of buildings.

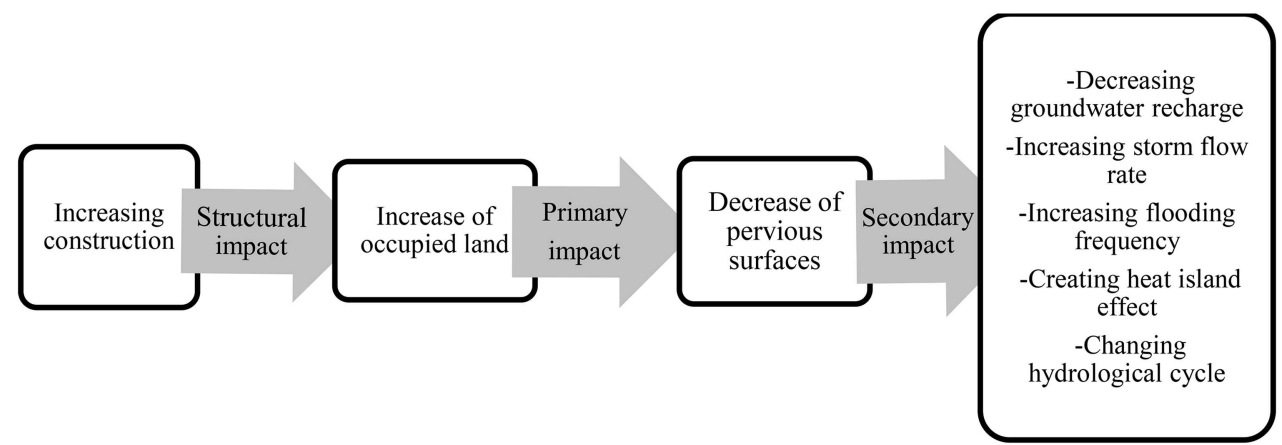

Figure 18. The primary and secondary effects of high-rise buildings on urban pervious surfaces. 


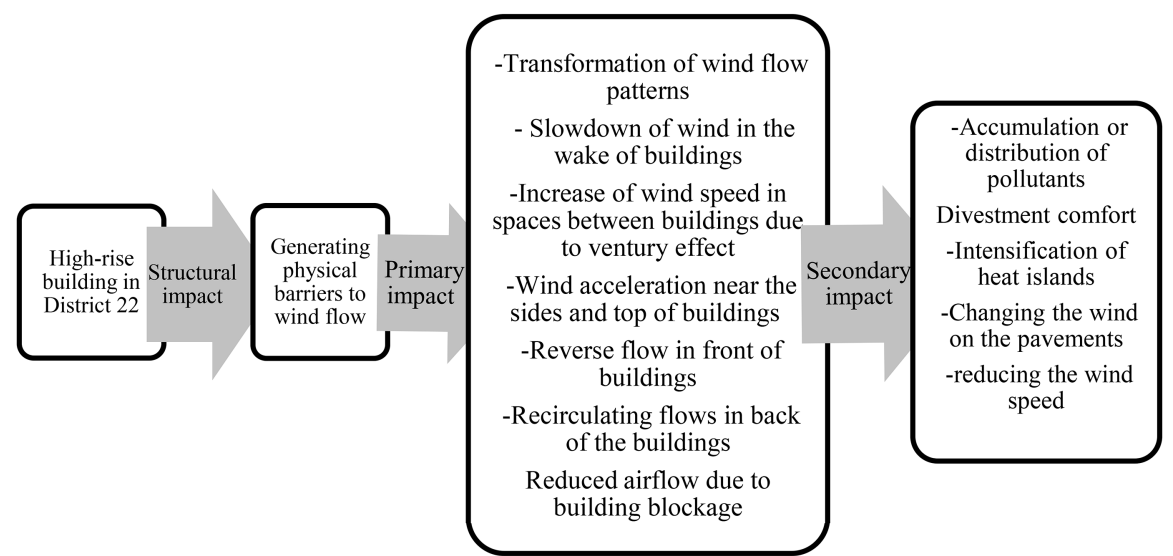

Figure 19. The primary and secondary effects of high-rise building construction on wind flow.

3. Number of buildings (third group);

4. Building orientation;

5. Sharp or rounded corners of the building (sharp corners cause separation, while rounded corners allow smoother wind flow);

6. Distance between buildings.

The distribution of high-rise buildings and their configurations has led to primary and secondary impacts on wind flows. As a result, despite the advantage of high-rise building strategies for the reduction of urban horizontal development and sprawl, the proper site selection of high-rise buildings is essential to reduce the negative impacts on the natural wind flow pattern. Figure 19 shows the primary and secondary effects of high-rise buildings on wind flow.

\section{Conclusions}

In this study, the environmental impacts of high-rise buildings were assessed using the resilient development mindset. The study was focused on three main issues:

- First, the implication of the resilient development mindset in environmental impact assessment;

- Second, the importance of protecting the permeable urban surfaces;

- Third, the importance of site selection of high-rise buildings with respect to wind blockage.

Protecting and restoring permeable surfaces in an urban environment is one of the important ecological factors in sustainability. Construction of the highrise building is a potential strategy for reducing the urban horizontal development growth and reducing impervious land area. Unfortunately, in Iran, there is no provision for protecting permeable urban surfaces through high-rise building policy. It should be noted that Tehran is struggling with many environmental problems, among which are the drop in groundwater level (about $18 \mathrm{~cm}$ per year) and occasional flooding that are exasperated by the scarcity of pervious land area. Actually, air pollution, flooding, and decline in the groundwater level are secondary effects due to the lack of attention to the protection of permeable urban surfaces and partial blockage of wind flow channels in Tehran.

District 22, located in the north-west of Tehran, is along one of the main wind flow channels of the Tehran municipality. Inappropriate location of high-rise buildings could cause undesirable changes in the speed and intensity of wind airflow. Consequently, it could affect air quality and, even, the level of air pollution.

Another important point addressed in this article is the importance of resilience mindset in assessing the environmental impacts. Based on the resilient development mindset, the differences between structural (change in land cover, permeable surfaces) and functional (air and water process) criteria can be identified. Such an understanding determines the important primary and secondary environmental consequences. As a result, the goal of sustainable development can be achieved through structural management instead of costly and time-consuming efforts to control the secondary effects and processes.

\section{References}

1. Maclean, I., Macken, K., Byrne, G., O'Mahony, T., and Archer, B., Guidelines on the Information to be Contained in Environmental Impact Statements, Ireland: Environmental Protection Agency (2002).

2. Rao, S.K., Environmental Impact Assessment Guidance Manual for Highways, Hyderabad: Administrative Staff College of India (2010).

3. Lohani, B., Evans, J.W., Ludwig, H., Richard, A., and Tu, S.L., Environmental Impact Assessment for Developing Countries in Asia, 1, Asia Development Bank (1997). 
4. Therivel, R., Wilson, E., Thompson, S., Heaney, D., and Pritchard, D., Strategic Environmental Assessment, London: Earth scan (1992).

5. Janes, C., Baker, M., Carte, J., Jays, S.M., and Wood, T., Strategic Environmental Assessment and Land Use Planning: An International Evaluation, London: Earth Scan (2005).

6. Schepherd, A. and Ortolano, L., Strategic Environmental Assessment for Sustainable Urban Development, Elsevier Science Inc (1996).

7. Jia, K., Xie, J., Zhang, W., and Cai, Y., Study on Environmental Impact Assessment of Land Use Planning, China Land Sc., pp. 15-20 (2003).

8. Curran, J., Wood, C., and Hilton, M. "Environmental appraisal of UK development plans: current practice and future directions", Environ Plan B, 25(3), pp. 411-433 (1998).

9. Alshawaikhat, H. "Strategic environmental assessment can help solve environmental impact assessment failures in developing countries", Environmental Impact Assessment Review, 25(1), pp. 307-317 (2005).

10. Fischer, T.B. and Gazzola, P. "SEA effectiveness Criteria-equally valid in all countries? The Case of Italy", Environmental Impact Assessment Review, 26(4), pp. 396-409 (2006).

11. Slootweg, R., and Jones, M. "Resilience thinking improves SEA: A discussion paper", Impact Assessment and Project Appraisal, 29(4), pp. 263-276 (2011).

12. Faith, C. and Kalle, H. "Resilience in the SEA of a connectivity strategy", Proceedings of Conference of International Association of Impact Assessment (IAIA), 31.05.-6.06.2011, Puebla, Mexico (2011).

13. Folke, C., Carpenter, S., and Walker, B. "Regime shifts resilience and biodiversity in ecosystem management", Annual Review in Ecology Evolution and Systematic, 35, pp. 557-581 (2004).

14. Adjer, W.N., Hoghes, T.P., Folke, C., Carpenter, S.R., and Rockstorm, J. "Social ecological resilience to coastal disasters", Science, 309(5737), pp. 1036-1039 (2005).

15. Fanghan, L., Yanxu, L., Jian, P., and Jiansheng, W. "Assessing urban landscape ecological risk through an adaptive cycle framework", Landscape and Urban Planning, 180, pp. 125-134 (2008).

16. Bond, A.J. and Morrison-Saunders, A. "Re-evaluating sustainability assessment: Aligning the vision and the practice", Environmental Impact Assessment Review, 31(1), pp. 1-7 (2011).

17. Wu, J. "Urban ecology and sustainability: The stateof-the-science and future directions", Landscape and Urban Planning, 125, pp. 209-221 (2014).

18. Alberti, M., Marzluff, J.M., Shulenberger, E., Gordon, B., Ryan, C., and Zumbrunnen, C. "Integrating humans into ecology: Opportunities and challenges for studying urban ecosystems", BioScience, 53(12), pp. 1169-1179 (2003).
19. Ribeiro, P.J. and Jardi, L.A. "Urban resilience: A conceptual framework", Sustainable Cities and Society, 50, p. 101625 (2019).

20. Walker, B. and Salt, D., Sustaining Ecosystems and People in a Changing World, Washington: Island Press (2006).

21. Pickett, S., Cadenasso, M.L., Grove, J.M., et al. "Urban ecological systems linking terrestrial ecological physical and socioeconomic components", Annual Review of Ecology and Systematic, 32, pp. 127-157 (2001).

22. Grimm, N.B., Grove, J.G., Pickett, S.T., and Redman, C.L. "Integrated approaches to long-term studies of urban ecological systems", BioScience, 50(7), pp. 571584 (2000).

23. Alberti, M. "The effects of urban pattern on ecosystem function", Integration Regional Science Review, 28, pp. 168-190 (2005).

24. Yu, Y., Kwok, K.C.S., Liu, X.P., and Zhang, Y. “Air pollutant dispersion around high-rise buildings under different angles of wind incidence", Journal of Wind Engineering and Industrial Aerodynamics, 167 (2017).

25. Cammelli, S. and Stanfield, R. "Meeting the challenges of planning policy for wind microclimate of high-rise developments in London", In Procedia Engineering, 198, pp. 43-51 (2017).

26. Jiachen, M., Wenwen, Y., and Naiping, G. "The transport of gaseous pollutants due to stack and wind effect in high-rise residential buildings", In Building and Environment, 94(Part 2), pp. 543-557 (2015).

27. Zhang, Y., Kwok, K.C.S., Liu, X.-P., and Niu, J.-L. "Characteristics of air pollutant dispersion around a high-rise building", In Environmental Pollution, 204, pp. 280-288 (2015).

28. Yuan, M., Yin, C., Sun, Y., and Chen, W. "Examining the associations between urban built environment and noise pollution in high-density high-rise urban areas: A case study in Wuhan, China", Sustainable Cities and Society, 50, p. 101678 (2019).

29. Giyasov, B. and Giyasova, I. "The impact of highrise buildings on the living environment", E3S Web of Conferences, 33, p. 01045 (2018).

30. Tehran meteorological organization, http://www. tehranmet.ir/ShowPage.aspx?page_=form\&order= show\&lang $=1 \&$ sub $=0 \&$ PageId $=32 \&$ PageIDF $=28 \&$ tempname $=$ maintehranair $(2016)$.

31. Tehran Municipality, Comprehensive Statistical Information of Tehran from 2006-2016 (2016). http://d2k.ir/product/97-tehran-statistical-book/

32. Tehran Municipality, Statistical Yearbook of Tehran (2013). http://tmicto.tehran.ir/Portals/0/Document/ Amarname/ NEW_PDF/AmarShahr/92-TehranS tatisticalYearBook.pdf

33. U.S. Geological Survey; (2019). Earth Explorer-Home. Retrieved 2018, https://earthexplorer.usgs.gov/

34. http://envi-met.software.informer.com/3.1/. 


\section{Biographies}

Hassan Vafai is an Emeritus Professor of Civil Engineering at Sharif University of Technology. In addition, he has held position of professorship in engineering at different universities including Washington State University, and University of Arizona. He has authored/coauthored numerous papers in the field of engineering including applied mechanics, biomechanics and structural engineering (steel, concrete, timber, and offshore structures). He was founder and editor-inchief of Scientia, international journal of science and technology. Throughout his careers, he has received numerous awards for his contribution to the promotion of science and technology worldwide including being elected "Eternal Spirit in Science," the highest honor by the National Academy of Sciences of Iran conferred on outstanding scientists; an honorary doctorate by the Senatus Academicus of Moscow Region State Institution of Higher Education; and the "Order of Palm Academicques" awarded by the Ministry of Education, Research and Technology of France.

Parastoo Parivar is a Researcher and Lecturer in the field of environmental planning. She received her $\mathrm{PhD}$ degree in Environmental Planning from the University of Tehran in 2013. She is currently an Assistant Professor at the Department of Environmental Engineering in Yazd University. Her research interests include urban ecological planning, urban resiliency, landscape ecology, environmental impact assessment of development projects, and ecological impacts of climate change.

Saviz Sehat Kashani is a faculty member of Atmospheric Science and Meteorological Research Center (ASMERC), Tehran, Iran. As a meteorologist, her research interests and publications include dust climatology as well as dust observation, monitoring, and nearcasting using remote sensing techniques. She has the honor of being the director of World Meteorological Organization (WMO), Regional Training Center (RTC) in Tehran, Iran, is a member of the steering committee of WMO Sand and Dust Storm Warning Advisory and Assessment System (SDS-WAS), and is as an expert in the Task Team on the Use of Remote Sensing Data for Climate Monitoring (TTURSDCM) of WMO.
Amir Farshforoush Imani is a Researcher in the field of fluid dynamics and Fluid-Structure Interaction (FSI). He is currently a PhD candidate in Ocean Engineering from Sharif University of Technology. His research interests include energy harvesting from wind and wave resources, meteorological investigation, offshore platforms engineering, micro- and micro-climate simulation.

Farane Vakili has a master degree from University of Tehran in the field of Environmental Planning. In addition, she works in the field of environmental education at schools. Her research interests include public participation, landscape ecology, environmental impact assessment.

Goodarz Ahmadi is a Clarkson Distinguished Professor and Robert R. Hill Professor of Mechanical and Aeronautical Engineering at Clarkson University. He has obtained his BS degree from Tehran University and his $\mathrm{MS}$ and $\mathrm{PhD}$ degrees from Purdue University. He is a Fellow of ASME, ASFTE, ISME, and ISCE. Among his many awards, he was the recipient of the 2016 ASME Freeman Scholar Award in Fluid Mechanics. He was also elected as the "Chehreh Mandegar" (Everlasting figure) in Mechanical Engineering in 2003. He is an honorary member of Academic of Science of Iran. He has four patents and authored three books and over 700 publications in archival journals. He also has made more than 1250 presentations including 20 plenary and keynotes in national and international technical conferences and has given more than 190 invited talks and short courses at other institutions. His research interests include multiphase flows, particle transport and deposition, turbulent flow control, granular flows, air pollution, flow through porous and fractured media, random vibrations, and structural mechanics. His research has been supported by the National Science Foundation, the Environmental Protection Agency, Department of Energy, NASA, AFOSR, NYSTAR, GE, Corning, IBM, Xerox, Kodak, and Dura Pharmaceutical. He has held many administrative positions at Clarkson University including the MAE Department Chair 1992-1995, the Associate Dean of Engineering 2003-2005, the Interim Vice Provost for Research 2004-2005, and the Dean of Engineering 2005-2015. Earlier, he served as the Dean of Engineering of Shiraz University. 